\title{
O $\mathrm{BONE} \& / \mathrm{O} / 1$ NON-OPERATIVE MANAGEMENT OF ANTERIOR CRUCIATE LIGAMENT INJURIES IN THE GENERAL POPULATION
}

\author{
PIERRE-PAUL CASTELEYN, FRANK HANDELBERG
}

From the Vrije Universiteit Brussel, Brussels, Belgium

The operative treatment of lesions of the anterior cruciate ligament (ACL) in athletes has been widely advocated and performed. We have investigated the outcome of non-operative management in a lowerdemand, general population. We reviewed a consecutive group of 228 patients, which excluded professional and high-level athletes, for two to 12 years after an ACL lesion had been diagnosed by arthroscopy.

There was a low incidence of secondary ACL and meniscal surgery, $5.4 \%$ and $3.5 \%$ respectively, and all these procedures were performed during the first three years after the ACL injury.

We studied a subgroup of 109 patients with follow-up of at least five years (mean 8.5 years) and evaluated them using the IKDC score. The general outcome was reasonably satisfactory, with $23 \%$ in grade $A, 50 \%$ in grade $B, 21 \%$ in grade $C$ and only $6.4 \%$ in grade $D$. We found no statistically significant prognostic effect within this group as regards age, activity levels, or the incidence of associated lesions.

J Bone Joint Surg [Br] ] 1996;78-B:446-51.

Received 25 August 1995; Accepted after revision 29 November 1995

Lesions of the anterior cruciate ligament (ACL) in athletes have been studied extensively in orthopaedic sports medicine, and operative treatment using grafts is widely advocated for this particular group of patients (Fetto and Marshall 1980; Noyes et al 1983a; Kannus and Järvinen 1987; Andersson et al 1989; Barrack et al 1990; Daniel and Fithian 1994). Many ACL lesions, however, are seen in nonathletes as a result of accidents or low-grade recreational activities (Jain, Swanson and Murdoch 1983; Casteleyn,

P.-P. Casteleyn, MD, Professor, Department of Human Anatomy and Associate Clinical Professor, Department of Orthopaedics and Traumatology.

F. Handelberg, MD, Assistant Clinical Professor

Deparment of Orthopaedics and Traumatology, Academisch Ziekenhuis,

AZ-VUB Laarbeeklaan 101, B-1090 Brussels, Belgium.

Correspondence should be sent to Professor P.-P. Casteleyn.

(C)1996 British Editorial Society of Bone and Joint Surgery 0301-620X/96/31176 \$2.00
Handelberg and Opdecam 1988). We aimed to investigate the outcome of the conservative treatment of ACL lesions in a lower-demand population.

\section{PATIENTS AND METHODS}

Over a period of 12 years, we managed a total of 274 patients with acute traumatic knee haemarthrosis. All had examination under anaesthesia and arthroscopy.

Of these, we treated 46 by ACL reconstruction. They included patients with gross or multidirectional joint laxity (grade-3 or grade-4 pivot shift, combined lesions of the $\mathrm{ACL}$ and lateral collateral ligament (LCL) or posterior cruciate ligament (PCL)) and in addition all high-level or professional athletes. These 46 cases $(16.8 \%)$ were excluded from the study group.

This left a consecutive group of 228 patients (83\%) who were managed conservatively. There was an almost fourfold male to female ratio and the mean age at the time of injury was 33.2 years (16 to 66 ). The main causes of injury were daily living activities (28.1\%), traffic accidents (11.8\%), and recreational activities $(60.1 \%)$ (Table I).

Initial management. In $83 \%$ of the cases, arthroscopic evaluation was within three weeks of the index injury. The proportions of isolated ACL ruptures and those associated with meniscal and ligamentous lesions were comparable with those reported in previous studies (Casteleyn et al 1988) (Tables I and II); only 21 of the ACL tears (9\%) were partial. Intrasynovial ACL lesions $(14 ; 6.1 \%)$ were left as much as possible within the synovial sheath. There was spontaneous partial reattachment of the distal ACL stump to the PCL in 18 knees (7.9\%): these were left undisturbed. Some ACL remnants which seemed likely to impinge between the femur and tibia and limit extension were trimmed. No reconstructive ACL surgery was performed during the initial arthroscopy.

Meniscal surgery was performed if indicated and feasible. Three of 27 torn lateral menisci and 17 of 105 medial menisci were sutured. Minor lesions, of one lateral and seven medial menisci, were left untreated. All other meniscal lesions $(77.1 \%$ of the medial and $85.2 \%$ of the lateral meniscal lesions) were treated by partial arthroscopic meniscectomy. No surgery was performed for medial collateral ligament (MCL) lesions. 
Table I. Details of the whole series and of the subgroups with secondary ACL and meniscal surgery

\begin{tabular}{|c|c|c|c|c|c|}
\hline & $\begin{array}{l}\text { Whole series } \\
(n=228)\end{array}$ & $\begin{array}{l}\text { ACL } \\
\text { surgery } \\
(n=11)\end{array}$ & p value & $\begin{array}{l}\text { Meniscal } \\
\text { surgery } \\
(n=7)\end{array}$ & p value \\
\hline Age in years & 33.2 & 26.5 & $<0.5$ & 31.5 & NS \\
\hline Male:female ratio & $4: 1$ & $2: 1$ & $<0.05$ & $4: 1$ & NS \\
\hline $\begin{array}{l}\text { Activity level (number; percentage) } \\
\qquad \begin{array}{l}1 \\
2 \\
3 \\
4\end{array}\end{array}$ & $\begin{aligned} 25 & (11.0) \\
119 & (52.2) \\
67 & (29.4) \\
17 & (7.5)\end{aligned}$ & $\begin{array}{l}1(9.1) \\
6(54.5) \\
3(27.3) \\
1(9.1)\end{array}$ & $\begin{array}{l}\text { NS } \\
\text { NS } \\
\text { NS } \\
\text { NS }\end{array}$ & $\begin{array}{l}1(14.3) \\
3(42.8) \\
2(28.6) \\
1(14.3)\end{array}$ & $\begin{array}{l}\text { NS } \\
\text { NS } \\
\text { NS } \\
\text { NS }\end{array}$ \\
\hline $\begin{array}{l}\text { Aetiology (number; percentage) } \\
\text { Activities of daily living } \\
\text { Traffic accidents } \\
\text { Recreation }\end{array}$ & $\begin{array}{r}64(28.1) \\
27(11.8) \\
137(60.1)\end{array}$ & $\begin{array}{l}3(27.3) \\
1(9.1) \\
7(63.6)\end{array}$ & $\begin{array}{l}\text { NS } \\
\text { NS } \\
\text { NS }\end{array}$ & $\begin{array}{l}2(28.6) \\
1(14.3) \\
4(57.1)\end{array}$ & $\begin{array}{l}\text { NS } \\
\text { NS } \\
\text { NS }\end{array}$ \\
\hline $\begin{array}{l}\text { Lesions (number; percentage) } \\
\text { Isolated ACL } \\
\text { ACL }+1 \text { other } \\
\text { ACL }+>1 \text { other }\end{array}$ & $\begin{array}{r}48(21.0) \\
108(47.4) \\
72(31.6)\end{array}$ & $\begin{array}{l}2(18.2) \\
5(45.5) \\
4(36.4)\end{array}$ & $\begin{array}{l}\text { NS } \\
\text { NS } \\
\text { NS }\end{array}$ & $\begin{array}{l}2(28.6) \\
3(42.9) \\
2(28.6)\end{array}$ & $\begin{array}{l}\text { NS } \\
\text { NS } \\
\text { NS }\end{array}$ \\
\hline
\end{tabular}

Table II. Lesions diagnosed during initial arthroscopy

\begin{tabular}{lcl}
\hline Lesions & Number & Percentage \\
\hline Isolated ACL & 48 & 21.05 \\
ACL + 1 other & 108 & 47.37 \\
ACL + >1 other & 72 & 31.58 \\
ACL + medial meniscus & 105 & 46.05 \\
$\quad$ + lateral meniscus & 27 & 11.84 \\
$\quad$ + medial collateral ligament & 64 & 28.07 \\
$\quad$ + lateral collateral ligament & 15 & 6.58 \\
$\quad$ + posterior cruciate ligament & 0 & 0.0 \\
\hline
\end{tabular}

All patients were treated by a comprehensive rehabilitation programme for six to eight weeks. Early weight-bearing was allowed with the eventual protection of a cast or a brace in cases of partial ACL and intrasynovial ACL, MCL and LCL lesions.

Follow-up. The initial 228 patients have been followed up for 2 to 12 years. Data were collected during annual examinations or by written questionnaire or telephone interviews. Of these patients, 25 (11\%) have been lost to follow-up leaving 203 with known results at over two years. Records were maintained of pre- and postinjury levels of activity and of the reasons for any long-term modification of the level of activity.

We classified activity levels into four groups:

1) strenuous activity which included jumping, pivoting and cutting (soccer);

2) moderate activity, involving heavy manual work (skiing, tennis);

3) light activity such as jogging or running; and

4) sedentary activity such as housework and the normal activities of daily living.

We recorded all subsequent surgery for the ACL lesion (intra-articular or extra-articular) and all subsequent meniscal surgery. These data were then used to construct survival tables with ACL or meniscal surgery or both considered as end-points. The age, gender, activity level, aetiology of the injury and any associated lesions in the patients who required secondary ACL and/or meniscal surgery were then compared with similar data from the patients who had no subsequent operations (Table I).

We tried to review all 132 patients with at least five years' follow-up for their subjective opinion, clinical examination, and radiological assessment. Of these, 23 (17\%) refused further clinical and radiological examination. The 109 patients who were studied in detail did not differ significantly from the initial cohort as regards mean age, gender, or distribution of activity level, cause of injury or associated lesions. The mean period from the initial injury was 8.5 years (5 to 12). The final assessment was recorded on the International Knee Documentation form (Hefti et al 1993). This assesses results in seven separate subgroups (see Table IV). These are subjective assessment, symptoms, range of motion, ligament examination (which in our study included use of the KT 2000 tester (Medmetric Corporation, San Diego, California) with $134 \mathrm{~N}$ displacement force), compartmental crepitus, radiography and a one-leg hop test. The result in each subgroup is scored on a four-point scale. The lowest grade determines the global grade of the subgroup, and the worst evaluation group determines the final score.

We tried to find correlations between the final grade and age at injury, associated lesions, activity level or modification and length of follow-up, using the analysis of variance, the paired $t$-test, and the Mann-Whitney $\mathrm{U}$ test.

\section{RESULTS}

Survival. Only 11 of the 203 patients followed for two to 12 years had needed secondary ACL surgery (5.4\%) and seven had secondary meniscal surgery (3.5\%) (Table I). All these procedures had been performed during the first three years after the index injury with none later than this. These figures 


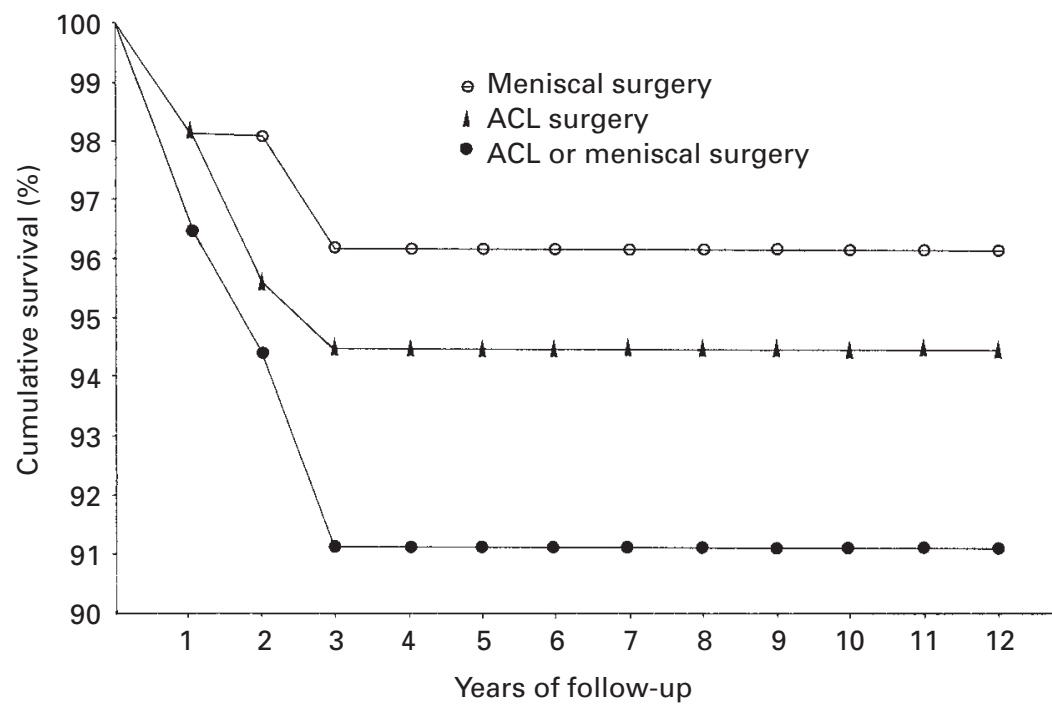

Fig. 1

Survival curves after non-operative management of ACL injuries, using as end-points secondary ACL surgery, secondary meniscal surgery, and both together.
Table III. Activity level modification after ACL injury in 203 patients

\begin{tabular}{lcc}
\hline & Number & Percentage \\
\hline Increase of 1 level & 4 & 2.0 \\
No modification & 112 & 55.2 \\
Decrease & & \\
$\quad$ 1 level & 39 & 19.2 \\
$\quad$ level & 20 & 9.9 \\
$\quad$ level & 28 & 13.8 \\
\hline
\end{tabular}

give a high survival rate which persists for three to 12 years (Fig. 1).

We found no correlation between survival and cause of injury, associated lesions or activity levels, but the patients who had needed subsequent ACL surgery were younger and had a lower male-to-female ratio (Table I).

Activity levels. The initial activity levels were those of a general population with a fair proportion of manual workers, some of them involved in moderate sport and recreational activities (Table I). None of the patients who needed secondary ACL and meniscal surgery had modified their activity level since the injury and its treatment. Less than half of all the patients had modified their activity levels after the ACL injury (Table III) and of those who reported a decrease, only $57(65.5 \%)$ considered that this decrease in activity level was related to their ACL injury.

As expected, the relationship between decrease in activity level and the original injury became less important with length of follow-up. Any decrease in activity was reported to be injury-related by $78 \%$ when it occurred less than five years after injury, by $57 \%$ between five and eight years, and by only $17 \%$ when it occurred after more than eight years.

IKDC examination. The results in 109 patients are summarised in Table IV. The subjective results were satisfactory: $82.4 \%$ of the patients stated that their knee was normal or nearly normal. This was confirmed by the rather benign nature of the symptoms; $61 \%$ achieved a normal grade and $21 \%$ a nearly normal grade. The range of motion was marginally limited in only $19 \%$, with no important extension or flexion deficits. The lowest grades were found as expected in the KT 2000 ligament examination subgroup, but even for this test $32.1 \%$ of the knees had a nearly normal grade. As regards compartmental crepitus $84 \%$ were normal and there was no radiological narrowing of the joint space in $76 \%$.

For the one-leg hop test, 57\% had normal rates; this confirmed the low intensity of any symptoms and the reasonably good function of most of the knees. The overall evaluations gave $23 \%$ in grade A, $50 \%$ in grade B, $21 \%$ in grade $\mathrm{C}$ and $6.4 \%$ in grade $\mathrm{D}$.

We could find no prognostic correlation between age at the time of injury, associated lesions, activity level at time of injury and at time of evaluation, and the final evaluation grade. There was no marked decrease in evaluation grades with increasing length of follow-up (Fig. 2).

\section{DISCUSSION}

The results of our study must be analysed with caution, since $11 \%$ of the patients were lost to follow-up, and $17 \%$ of the patients whom we traced at over five years refused further clinical examination. The main strength of our work is that the population of patients was selected at the time of the initial injury; many previous studies of the non-operative management of ACL injuries were based on patients who were seeking further treatment because of significant complaints (Fetto and Marshall 1980; McDaniel and Dameron 1980; Giove et al 1983; Noyes et al 1983a; Finsterbush et al 1990).

The conservative management which we used during the 14 years of the study must be considered in relation to the 
Table IV. IKDC evaluation of 109 patients. The numbers in bold type are the global results for each group (see text)

\begin{tabular}{|c|c|c|c|c|c|c|c|c|}
\hline \multirow[b]{3}{*}{ Group } & \multicolumn{8}{|l|}{ Grade } \\
\hline & \multicolumn{2}{|l|}{$\overline{\mathrm{A}}$} & \multicolumn{2}{|l|}{ B } & \multicolumn{2}{|l|}{$\mathbf{C}$} & \multicolumn{2}{|l|}{ D } \\
\hline & Number & Percentage & Number & Percentage & Number & Percentage & Number & Percentage \\
\hline Subjective assessment & 33 & 30.3 & 57 & 52.3 & 18 & 16.5 & 1 & 0.9 \\
\hline Function & 33 & 30.3 & 55 & 50.5 & 21 & 19.3 & 0 & \\
\hline Impact on activity & 38 & 34.9 & 56 & 51.4 & 14 & 12.8 & 1 & 0.9 \\
\hline Symptoms & 67 & 61.5 & 23 & 21.1 & 14 & 12.8 & 5 & 4.5 \\
\hline Pain & 88 & 80.7 & 14 & 12.8 & 6 & 5.5 & 1 & 0.9 \\
\hline Swelling & 98 & 89.9 & 6 & 5.5 & 4 & 3.6 & 1 & 0.9 \\
\hline Partial giving-way & 70 & 64.2 & 22 & 20.2 & 13 & 11.9 & 4 & 3.7 \\
\hline Full giving-way & 93 & 85.3 & 10 & 9.1 & 6 & 5.5 & 0 & \\
\hline Range of motion & 88 & 80.7 & 21 & 19.2 & $\mathbf{0}$ & & $\mathbf{0}$ & \\
\hline Extension lack & 97 & 88.9 & 12 & 11.0 & $\mathbf{0}$ & & 0 & \\
\hline Flexion lack & 104 & 95.4 & 5 & 4.5 & $\mathbf{0}$ & & 0 & \\
\hline Ligament examination & 35 & 32.1 & 52 & 47.7 & 21 & 19.2 & 1 & 0.9 \\
\hline Lachmann & 60 & 55.0 & 48 & 44.0 & 1 & 0.9 & 0 & \\
\hline End-point & 91 & 83.4 & & 18 & 16.5 & & & \\
\hline $70^{\circ}$ drawer & 65 & 59.6 & 39 & 35.8 & 5 & 4.6 & 0 & \\
\hline Medial joint opening & 40 & 36.7 & 64 & 58.7 & 4 & 3.7 & 1 & 0.9 \\
\hline Lateral joint opening & 97 & 89.0 & 12 & 11.0 & & & 0 & \\
\hline Pivot shift & 39 & 35.8 & 53 & 48.6 & 16 & 14.7 & 1 & 0.9 \\
\hline Crepitus & 93 & 85.3 & & & 15 & 13.8 & 1 & 0.9 \\
\hline Patellofemoral & 104 & 95.4 & & & 4 & 3.7 & 1 & 0.9 \\
\hline Medial compartment & 98 & 89.9 & & & 11 & 10.1 & 0 & \\
\hline Lateral compartment & 107 & 98.1 & & & 2 & 1.8 & 0 & \\
\hline Joint narrowing (radiological) & 83 & 76.2 & & & 21 & 19.3 & 5 & 4.6 \\
\hline Medial & 84 & 71.1 & & & 20 & 18.4 & 5 & 4.6 \\
\hline Lateral & 95 & 87.2 & & & 13 & 11.9 & 1 & 0.9 \\
\hline Patellofemoral & 87 & 79.8 & & & 18 & 16.5 & 4 & 3.7 \\
\hline Hop test & 63 & 57.8 & 40 & 36.7 & 4 & 3.7 & 2 & 1.8 \\
\hline Final evaluation & 25 & 22.9 & 54 & 49.5 & 23 & 21.1 & 7 & 6.4 \\
\hline
\end{tabular}

evolving knowledge on ligament healing; some of our earliest patients were treated during the early 1980s. We would not now use casting for ligament sprains or partial ruptures of the ACL (Daniel et al 1994).

Our review of a general patient population, less interested in sporting activities, also means that precise data about physical activity are more difficult to obtain. The IKDC assessment form does not offer the same refinement of analysis as the Tegner score, but seems to be more applicable to this type of population. It should also be noted that the mean time between injury and latest radiological examination in our 103 patients ( 8.5 years; 5 to 12 ) may be too

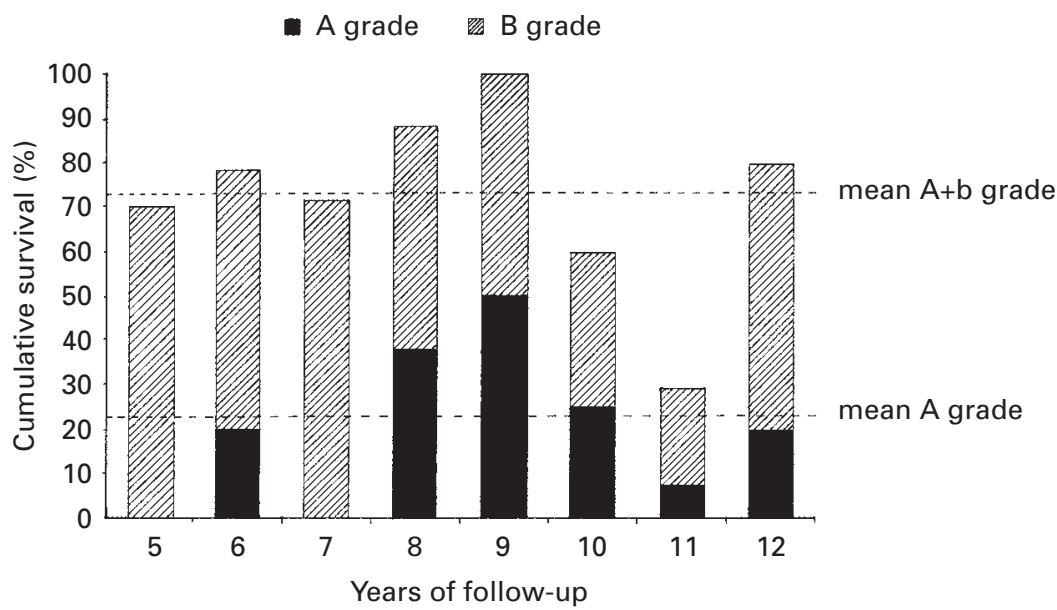

Fig. 2

Changes in the proportions of A and B global evaluation grades with length of follow-up showing no significant deterioration. 
short to show significant degenerative changes in this lowdemand population.

The most surprising result of our study was the fairly limited laxity shown by ligament examination; only $44.9 \%$ of Lachmann tests showed side-to-side differences of more than $3 \mathrm{~mm}$, and only $15.5 \%$ showed gross pivot shifts. Among possible explanations are the exclusion from the study of knees with gross instability and the appreciable percentages of isolated ACL lesions, intrasynovial lesions, and spontaneous reattachments to the PCL. Other factors may be a rehabilitation programme designed to protect and enhance the healing of the secondary knee restraints, and the population which included many heavy manual workers who do not undertake jumping, cutting and pivoting activities.

The low rate of meniscal injuries and the absence of meniscal surgery later than three years after the index injury are also rather surprising. The same factors and the progressive reduction of activity levels with time may provide an explanation. Only actual surgery on the menisci was recorded, and it is possible that some meniscal lesions in this low-demand population produced only slight symptoms which did not result in recorded meniscal surgery. For obvious ethical and economical reasons, it was impossible to conduct second-look arthroscopic or MRI examinations to provide more rigorous data on secondary meniscal lesions. Most of the recent papers on ACL lesions deal mainly with athletic or high-demand patient populations, and many focus on the poor results of conservative treatments in this population, with their high incidence of secondary injuries (Noyes et al 1983a; Finsterbush et al 1990), degenerative changes (Fetto and Marshall 1980; Kannus and Järvinen 1987; Pattee et al 1989), cessation of sport activities (Andersson et al 1989; Sommerlath, Lysholm and Gillquist 1991) and on the need for secondary joint stabilisation (Noyes et al 1983b; Barrack et al 1990). These reports led to the concept that only surgical reconstruction could allow unrestricted return to sport and prevent secondary problems (Daniel and Fithian 1994).

This view remains controversial: a recent study failed to show a higher proportion of contact sports participation at seven years after surgical reconstruction as compared with conservative treatment (Roos et al 1995). It has also been shown that subsequent degenerative changes cannot be avoided, even after the latest surgical techniques which take full account of ACL anatomy and biomechanics (Sommerlath and Gillquist 1992). Such degenerative changes may be less important in conservatively treated patients (Daniel et al 1994); our limited data support these observations. Various hypotheses have been put forward to explain subsequent degeneration in apparently stable knees.

The extent of concomitant meniscal injury is of course important, but its influence has not been proven (Daniel et al 1994; Küllmer, Letsch and Turowski 1994). Bone 'bruises', sustained at the time of injury, may perhaps damage the subchondral bone (Graf et al 1993; Fowler 1994). Even the geometry of the femoral condyle has been evoked (Friden et al 1993). The mechanical properties of articular cartilage (Setton et al 1994) and changes in synovial fluid cytokines (Cameron et al 1994) have been reported to be influenced by the initial ACL lesion; these changes may help to induce degenerative changes in a reconstructed knee which is subjected to further high-demand activities.

Our long-term study indicates that patients who are willing to avoid these activities can have acceptable functional results after non-operative treatment of an ACL injury. The outcome does not appear to deteriorate with time, and includes only very limited osteoarthritic changes. Our findings support previous short-term and medium-term reports on the conservative treatment of ACL injuries (Giove et al 1983; Satku, Kumar and Ngoi 1986; Buss et al 1995). Despite the very numerous publications on the subject, the management of ACL lesions is almost as controversial today as it has been for 50 years (Lindstrand 1995).

No benefits in any form have been received or will be received from a commercial party related directly or indirectly to the subject of this article.

\section{References}

Andersson C, Odensten M, Good L, Gillquist J. Surgical or non-surgica treatment of acute rupture of the anterior cruciate ligament. J Bone Joint Surg [Am] 1989;71-A:965-74.

Barrack RL, Bruckner JD, Kneisl J, Inman WS, Alexander AH. The outcome of nonoperatively treated complete tears of the anterior cruciate ligament in active young adults. Clin Orthop 1990;259:192-

Buss DD, Min R, Skyhar M, et al. Nonoperative treatment of acute anterior cruciate ligament injuries in a selected group of patients. Am J Sports Med 1995;23:160-5.

Cameron ML, Fu FH, Paessler HH, Schneider M, Evans CH. Synovial fluid cytokine concentrations as possible prognostic indicators in the ACL-deficient knee. Knee Surg Sports Traumatol Arthroscopy 1994;2:38-44.

Casteleyn PP, Handelberg F, Opdecam P. Traumatic haemarthrosis of the knee. J Bone Joint Surg [Br] 1988;70-B:404-6.

Daniel DM, Fithian DC. Indications for ACL surgery. Arthroscopy 1994; 10:434-41.

Daniel DM, Stone ML, Dobson BE, et al. Fate of the ACL-injured patient: a prospective outcome study. Am J Sports Med 1994;22:632-44.

Fetto JF, Marshall JL. The natural history and diagnosis of anterior cruciate ligament insufficiency. Clin Orthop 1980;147:29-38.

Finsterbush A, Frankl U, Matan Y, Mann G. Secondary damage to the knee after isolated injury of the anterior cruciate ligament. Am J Sports Med 1990;18:475-9.

Fowler PJ. Bone injuries associated with anterior cruciate ligament disruption. Arthroscopy 1994;10:453-60.

Friden T, Jonsson A, Erlandsson T, Jonsson K, Lindstrand A. Effect of femoral condyle configuration on disability after an anterior cruciate ligament rupture: 100 patients followed for 5 years. Acta Orthop Scand 1993;64:571-4

Giove TP, Miller SJ III, Kent BE, Sanford TL, Garrick JG. Nonoperative treatment of the torn anterior cruciate ligament. J Bone Joint Surg [Am] 1983;65-A:184-92.

Graf BK, Cook DA, De Smet AA, Keene JS. 'Bone bruises' on magnetic resonance imaging evaluation of anterior cruciate ligament injuries. Am J Sports Med 1993;21:220-3

Hefti F, Müller W, Jakob RP, Stäubli H.-U. Evaluation of knee ligament injuries with the IKDC form. Knee Surg Sports Traumatol Arthroscopy 1993;1:226-34.

Jain AS, Swanson A, Murdoch G. Hemarthrosis of the knee joint. Injury $1983 ; 15: 178-81$. 
Kannus P, Järvinen M. Conservatively treated tears of the anterior cruciate ligament: long-term results. J Bone Joint Surg [Am] 1987;69-A:100712 .

Küllmer K, Letsch R, Turowski B. Which factors influence the progression of degenerative osteoarthritis after ACL surgery?. Knee Surg Sports Traumatol Arthroscopy 1994;2:80-4.

Lindstrand A. The anterior cruciate ligament problem. Acta Orthop Scand 1995;66:105-6.

McDaniel WJ Jr, Dameron TB Jr. Untreated ruptures of the anterior cruciate ligament: a follow-up study. J Bone Joint Surg [Am] 1980;62-A:696705.

Noyes FR, Mooar PA, Matthews DS, Butler DL. The symptomatic anterior cruciate-deficient knee. Part I. The long-term functional disability in athletically active individuals. J Bone Joint Surg [Am] 1983a;65-A:15462.

Noyes FR, Matthews DS, Mooar PA, Grood ES. The symptomatic anterior cruciate-deficient knee. Part II. The results of rehabilitation, activity modification and counselling in functional disability. J Bone Joint Surg [Am] 1983b;65-A:163-74.
Pattee GA, Fox JM, Del Pizzo W, Friedman MJ. Four to ten year followup of unreconstructed anterior cruciate ligament tears. Am J Sports Med 1989; $17: 430-5$.

Roos H, Ornell M, Gärdsell P, Lohmander LS, Lindstrand A. Soccer after anterior cruciate ligament injury: an incompatible combination? A national survey of incidence and risk factors and a 7-year follow-up of 310 players. Acta Orthop Scand 1995;66:107-12.

Satku K, Kumar JP, Ngoi SS. Anterior cruciate ligament injuries: to counsel or operate?. J Bone Joint Surg [Br] 1986;68-B:458-61.

Setton LA, Mow VC, Müller FJ, Pita JC, Howell DS. Mechanical proprieties of canine articular cartilage are significantly altered following transection of the anterior cruciate ligament. J Orthop Res 1994; 12:45163.

Sommerlath K, Lysholm J, Gillquist J. The long-term course after treatment of acute anterior cruciate ligament ruptures: a 9 to 16 year followup. Am J Sports Med 1991;19:156-62.

Sommerlath K, Gillquist J. The long term course of various meniscal treatments in anterior cruciate ligament deficient knees. Clin Orthop 1992;283:207-14. 